\title{
THE LONG-TERM EFFECT OF HEALTH INSURANCE ON NEAR-ELDERLY HEALTH AND MORTALITY
}

\author{
BERNARD BLACK \\ JOSÉ-A N TONIO ES P ÍN-SÁNCHEZ \\ ERIC FRENCH \\ KATE LITVAK
}

\begin{abstract}
We use the best available longitudinal data set, the Health and Retirement Study, and a battery of causal inference methods to provide both central estimates and bounds for the long-term effect of health insurance on health and mortality among the near-elderly (initial age 50-61) over a 20-year period. Compared with matched insured persons, those uninsured in 1992 consume fewer health-care services, but their health (while alive) does not deteriorate relative to the insured, and, in our central estimates, they do not die significantly faster than the insured. Our upper and lower bounds suggest that prior studies have greatly overestimated the health and mortality benefits of providing health insurance to the uninsured.
\end{abstract}

KEYWORDS: health insurance, mortality

JEL CLASSIFICATION: I13

\section{Introduction}

We estimate the long-term effect of health insurance on mortality, health while alive, and health-care utilization, for the near-elderly in the United States. We study the near-elderly (initial age from 50 to 61 when first observed in 1992) because they are the group for whom an effect of health insurance on mortality and health is most likely to be found: the elderly are all insured; the young are healthier. We use (1) the best available longitudinal data set for studying the near-elderly, the Health and Retirement Study; (2) a long time series from initial observation in 1992 through 2012; and (3) a battery of modern causal inference methods.

The effect of health insurance on health outcomes is of high policy salience. The Affordable Care Act 2010 is a major investment in expanding access to health insurance. An important motive for this investment is the belief that, in President Barack Obama's words,

Bernard Black (corresponding author, bblack@kellogg.northwestern.edu), Northwestern University, Pritzker School of Law and Kellogg School of Management. José-Antonio Espín-Sánchez, Yale University, Department of Economics. Eric French, University College London, Department of Economics, and Federal Reserve Bank of Chicago. Kate Litvak, Northwestern University, Pritzker School of Law. 
access to health insurance is "life-or-death stuff. Tens of thousands of Americans die each year just because they don't have health insurance" (Goodnough, Pear, and Perez-Peña 2013, A1). That claim is based on prior "pure observational studies," which find that lack of health insurance predicts much higher mortality. ${ }^{1}$

An initial question is whether a pure observational study, such as ours, is a useful research design for studying the effects of health insurance on health and mortality, given the potential for selection bias in such a study, arising from unobserved differences between the insured and the uninsured. For studying long-term effects of health insurance, we believe the answer is yes: a pure observational study is the best design that is currently available-or likely to be available in the foreseeable future. Several studies use experimental and quasi-experimental designs to study the short-term effects of health insurance on mortality. Most find small effects. However, the long-term effects of insurance could well be larger than any short-term effects. There have been no long-term experimental or quasi-experimental studies of long-term effects.

Relative to prior observational studies, we make progress on-but do not solve, nor claim to-the core challenge posed by selection bias. We (1) use a more complete set of covariates; (2) use a much longer time period; (3) show how estimates vary with time since initial observation; (4) provide both central estimates (from comparing the uninsured to all insured, whether privately or publicly insured), and upper and lower bounds on those estimates (from comparing the uninsured separately to the privately insured and the publicly insured); (5) provide separate estimates for the uninsured and the insured; and (6) use a battery of methods rather than only one, to assess whether our estimates are sensitive to choice of method.

We measure insurance status at initial observation in 1992, consider the uninsured to be treated, and compare them to three control groups: the privately insured (below, "private controls"), the publicly insured ("public controls"), and all insured ("all controls"). We estimate the value of insurance for the uninsured (the average treatment effect for the treated, or ATT), the already insured (the average treatment effect for the controls, or ATC), and the whole sample (the average treatment effect, or ATE). The ATT estimates address the value of insuring the currently uninsured, and thus are likely to be of principal policy interest.

We find no evidence that the uninsured die significantly faster than the insured, for at least 14 years after initial observation. Our central ATT estimates for the extra mortality of the uninsured, compared with all insured, are close to zero. We find mild evidence of higher mortality after 16-20 years in some specifications. However, this apparent higher mortality is not statistically significant in our principal specification, in which we use inverse propensity weights (IPW) plus linear regression. In this specification, the coefficient on an uninsurance dummy is $0.017(\mathrm{t}=1.03)$ after 16 years and $0.028(\mathrm{t}=1.64)$ after 20 years. We can also compute hazard rates: the mortality rate for the uninsured, divided by the mortality rate for the insured. Those hazard rates are 1.06 at 16 years and 1.07 at

1 The principal studies are Franks, Clancy, and Gold (1993); McWilliams et al. (2004); Hadley and Waidmann (2006); Baker, Sudano, et al. (2006); and Wilper et al. (2009). Kronick (2009) finds no significant effect of insurance on mortality. 
20 years. With a simpler specification-IPW without regression - the hazard rates are even closer to 1 (equal mortality)-1.00 at 16 years and 1.02 at 20 years.

We also compare the health of the uninsured to that of the insured, while still alive. We find no evidence that the uninsured become less healthy over time, across an array of measures of health status.

We find evidence of treatment heterogeneity-different estimates of the value of insurance for the insured and the uninsured. The estimated value of insurance in reducing mortality for the insured, although statistically insignificant is generally higher than the estimated value for the currently insured. This is consistent with persons with more to gain from being insured often managing to obtain insurance.

We find, consistent with prior studies, that being uninsured reduces health-care utilization. The uninsured visit the doctor and are admitted to a hospital less often, are less likely to have prescription drugs prescribed, and are more likely not to take prescribed drugs for financial reasons. This lower use in earlier years does not lead to higher use once the initially uninsured reach Medicare age.

In the Online Appendix, available on the journal website (see http://www.mitpress journals.org/doi/suppl/10.1162/ajhe_a_00076) and on SSRN, we reconcile our results with what we view as the best prior observational study, McWilliams et al. (2004) (below MZMA). MZMA use the same data set we do, and find a large mortality benefit from health insurance, measured eight years after initial observation (hazard rate $=1.43 ; 95$ percent confidence interval, $\mathrm{CI},=[1.10,1.85])$. MZMA and other prior studies that reach similar conclusions overestimate the benefits of health insurance because of a combination of (1) comparing the uninsured only to the privately insured; (2) employing weaker controls for selection into health insurance status; and (3) failing to allow for treatment effect heterogeneity.

The confidence intervals for our central ATT estimates versus all insured do not rule out moderate effects of health insurance, but do exclude the point estimates from most prior studies. For example, our central 10-year ATT hazard ratio estimate, for the uninsured versus all insured, is 1.02 (95 percent $\mathrm{CI}=[0.87,1.17])$. The upper end of the 95 percent CI is well below MZMA's point estimate of 1.43 .

We bound our central estimates, obtained by comparing the uninsured with all insured, by comparing the uninsured separately with the privately insured and the publicly insured. The privately insured appear healthier than the uninsured, based on the covariates we can observe. It is likely that they are also healthier based on other covariates we cannot observe (positive selection). If so, we would expect them to live longer than the uninsured, even if both groups were insured or both groups were uninsured. Conversely, the publicly insured would likely die sooner than the uninsured if they were also uninsured (negative selection). Consistent with these priors, ATT estimates for the uninsured versus the publicly insured are often (though not always) negative, albeit usually statistically insignificant. Thus, comparing the uninsured separately with the privately insured and the publicly insured can provide rough upper and lower bounds on the true ATT. Those bounds are $[-0.029,0.020]$ at 10 years and $[-0.039,0.052]$ at 20 years. ${ }^{2}$ The upper

2 The lower bound is given by the coefficient versus the publicly insured minus one standard deviation, and the upper bound is the coefficient versus the privately insured plus one standard deviation. 
bounds are well below the point estimates from most prior studies. Moreover, the lower bounds from comparing the uninsured with public controls are much higher (closer to zero) than point estimates obtained using MZMA's methods. These tighter bounds suggest that while some selection effects probably remain, their magnitude is well below that in prior studies.

Another way to assess the importance of selection effects, and thus the credibility of our estimates, relies on the time dimension. Our ATT estimates of extra mortality for the uninsured versus all insured suggest that the effect of having health insurance in 1992 on future mortality is near zero through age 14, and provide mild evidence that insurance slightly reduces mortality after 16-20 years after initial observation. Yet by year 16, the sample mean age is 72, well above the Medicare-eligibility age of 65. Our priors, when we began this study, were that any impact of prior uninsurance on mortality would decline once most of the sample was covered by Medicare. Our ATT estimates instead rise. This suggests that the insured (most of whom are privately insured) may have unobserved characteristics that predict longer-term longevity.

Despite the likely presence of some remaining selection effects, we contribute to the literature on whether and how health insurance affects health and mortality in several ways. First, we bring estimates for the uninsured versus private and public controls closer to each other and thus provide tighter bounds on the likely true effect of health insurance on mortality. Second, we show that treatment heterogeneity is important, and provide estimates that allow for heterogeneity. Third, we estimate the effects of health insurance over time. Fourth, we assess the sensitivity of our estimates across several causal inference methods, rather than using a single method. Across methods and measures, health insurance moderately increases use of health-care services, but we find only weak evidence that uninsurance predicts either worse health or higher mortality.

There are two important caveats for our study. First, we measure insurance status in 1992, at the inception of the Health and Retirement Study. We cannot measure the effect of long-term uninsurance because the sample of long-term uninsured is too small. Second, enhanced access to health insurance could improve longevity for some segments of the population but not others. In particular, our study might find small effects of expanding health insurance because those who most need insurance often obtain it, and because federal law ensures emergency care to all who need it, insured or not. This paper proceeds as follows. Section II provides a literature review and discusses methodological concerns with prior studies. Section III discusses our data and estimation methods. Section IV presents our principal results for mortality. Section V presents results for health-care utilization and health. Section VI discusses some implications of our results; Section VII concludes. An Online Appendix provides additional results.

\section{Literature Review and Methodological Background}

We review in this section the principal prior studies of the impact of health insurance on mortality. See Dor and Umapathi (2014) for a more complete review. We discuss in later sections studies of the impact of health insurance on health-care utilization and on health while alive. 


\section{A. PRIOR PURE OBSERVATIONAL STUDIES}

Much of the research and policy analysis on the value of health insurance relies on pure observational studies. A well-known example is an Institute of Medicine (IOM 2002) report, which estimates that uninsurance increases mortality by 25 percent, implying 18,000 lives saved in $2001 .^{3}$ This and similar estimates have played a prominent role in the policy debate over expanding access to health insurance.

All prior studies compare the uninsured with the privately insured, exclude the publicly insured, and estimate only ATE. Franks, Clancy, and Gold (1993) use the NHANES survey and find 25 percent higher risk of mortality among the uninsured ( 95 percent CI $=[1.00,1.55]) .{ }^{4}$ McWilliams et al. (2004) (below, MZMA) is, in our judgment, the best of the studies that finds large mortality gains from health insurance. Because it is the best and uses the same Health and Retirement Survey (HRS) data set we use, we discuss their results in detail in the Online Appendix, and contrast our results to theirs. MZMA use the first five waves of the HRS (1992-2000). They estimate each person's propensity to be insured and use the propensity scores to reweight the sample. If selection only on observables (SOO) is satisfied, propensity score reweighting can produce unbiased treatment effect estimates.

Hadley and Waidmann (2006) use a subset of the HRS who were uninsured or had private or Veterans Administration (VA, here and below, including CHAMPUS) insurance. They assume that the impact of uninsurance on health is proportional to the number of waves in which a respondent is uninsured. Hadley and Waidmann estimate that being continuously uninsured would increase mortality by an implausible factor of 3.3 times. However, Kronick (2006) criticizes the plausibility of their instruments and other aspects of their methods. ${ }^{5}$

Baker, Sudano, et al. (2006) study the first six waves of the HRS. In regression analyses, uninsurance predicts 35 percent higher mortality risk (95 percent $\mathrm{CI}=[1.2,1.62]$ ), relative to the privately insured. Wilper et al. (2009) use NHANES and find 40 percent higher mortality for the uninsured $(95$ percent $\mathrm{CI}=[1.06,1.84]){ }^{6}$ In contrast, Kronick (2009)

3 The Institute of Medicine draws principally on Franks, Clancy, and Gold (1993) (discussed in text) and Sorlie et al. (1994) (not discussed because they do not control for health status). Dorn (2008) and Families USA (2012) use the IOM estimate of a 25 percent increase in mortality risk and provide larger, updated estimates of annual lives saved.

4 NHANES is the National Health and Nutrition Examination Survey. For details on the NHANES series, see http://www.cdc.gov/nchs/surveys.htm.

5 Their instrumental variables are spouse's union membership, immigrant status, years in the United States if foreign born, and involuntary job loss in last five years. None are likely to satisfy the "exclusion restriction" that the instrument must predict health status only through insurance, not directly or through an omitted variable (such as income or wealth, which they oddly do not use as covariates). A number of other studies also use instrumental variables (see the review by Dor and Umapathi (2014)). We are not convinced that any satisfy the exclusion restriction.

6 Wilper et al. (2009) report that in robustness checks, they added a propensity score to their regression model. This will not produce unbiased treatment effect estimates, even under unconfounded assignment. See Wooldridge (2010, eq. 21.52), for a correct approach. 
uses data from the National Health Insurance Survey, linked to mortality records, and finds no significant relation between mortality and private insurance.

Polsky et al. (2009) use the HRS to estimate transition probabilities for changes in health status and find no evidence that reaching Medicare age significantly affects these probabilities for the previously uninsured. Dor, Sudano, and Baker (2006) find small, generally insignificant improvements in a summary health measure for the uninsured over the first four years of the HRS in OLS regressions. ${ }^{7}$ Baker, Feinglass, et al. (2006) report that overall health improves for the uninsured in the first HRS wave when they are first covered by Medicare, relative to the previously insured, but small gains in the next wave. Courtemanche and Zapata (2014) study the Massachusetts coverage expansion in 2006 and find statistically significant but "economically" very small gains in self-reported health and some other health outcomes, for Massachusetts relative to control states.

All of these studies raise methodological concerns. First, almost all compare the uninsured with the privately insured, and exclude the publicly insured. The asserted justification, from MZMA, is that "Adults with public insurance were likely to have qualifying medical conditions (for example, end-stage renal disease) or disabilities not fully measured by the HRS that could have biased our results" (225). The publicly insured indeed have higher mortality than the uninsured. But to exclude them undermines the basis for causal inference. If assignment is confounded for the uninsured versus the publicly insured, one cannot credibly assert that it is unconfounded for the uninsured versus the privately insured.

\section{B. EXPERIMENTAL AND QUASI-EXPERIMENTAL STUDIES OF SHORT-TERM EFFECTS}

Several studies exploit randomized or natural experiments, and address whether insurance affects near-term health or mortality. These studies do not assess long-term effects. The Oregon Health Insurance Experiment studies Medicaid expansion. It finds small, statistically insignificant effects of health insurance on mortality and on most measures of health over the two years for which the experiment ran. ${ }^{8}$ Weathers and Stegman (2012) study a randomized experiment in which some uninsured Social Security Disability Insurance recipients received Medicare immediately, while others had to wait two years for coverage, and find no significant effect of earlier insurance on mortality.

Card, Dobkin, and Maestas (2009) and Finkelstein and McKnight (2008) exploit the discontinuity in health insurance coverage at age 65, when all US citizens and permanent residents become Medicare-eligible, to assess the impact of health insurance on mortality.

7 Dor, Sudano, and Baker (2006) find a much larger improvement in an instrumental variable analysis, but we do not view their instruments (state marginal income tax rates, percentage of state workers who belong to unions, and unemployment rate) as credible. Hadley and Waidmann (2006), discussed above, also use implausible instruments, and find that the health of the uninsured deteriorates prior to age 65. Earlier studies using shorter time periods include Baker et al. $(2001,2002)$ and Kasper, Giovannini, and Hoffman (2000).

8 See Allen et al. (2010), Finkelstein et al. (2012), and Baicker et al. (2013). This study found that the insured are less likely to be depressed, but no other significant changes in health. 
They find no evidence of a fall in overall mortality at age 65 . This null result is implicit in the published version of Card, Dobkin, and Maestas (2008), but explicit in their NBER working paper (2004). Card, Dobkin, and Maestas (2009) find a small post-65 reduction in mortality following emergency hospital admission. Chay, Kim, and Swaminathan (2010) find a reduction in mortality at age 65 when Medicare is introduced in the 1960s, but this effect weakens over time. Lichtenberg (2002) find a reduction in mortality at age 65, but Kronick (2009) reports, citing Dow (2004), that this is an artifact of how the Social Security Administration constructs the life tables that Lichtenberg used. Polsky et al. (2009) find no reduction in mortality risk for the previously uninsured after they become Medicareeligible. In Japan, Shigeoka (2014) finds little effect on health or mortality from a sharp reduction in patient cost-sharing at age 70 .

Sommers, Baicker, and Epstein (2012) use a differences-in-differences (DiD) design to study general Medicaid expansions in three states. They find large mortality gains in New York, positive but insignificant mortality gains for Arizona, and higher mortality for Maine. Sommers, Long, and Baicker (2014) find large mortality gains in Massachusetts following its health insurance expansion in 2007. Some of the point estimates in these papers are far too large to be due to health insurance alone. For example, Sommers, Long, and Baicker (2014) estimate a drop in health-care amenable mortality of 4.5 percent, and a 6.8 percent drop in the uninsurance rate. If lower mortality was entirely among the newly insured, a Wald estimate suggests a 4.5 percent $/ 0.068=66$ percent drop in amenable mortality for the newly insured, within two years after gaining coverage. This is implausible and inconsistent with the short-term studies cited above. It may be that single- or severalstate $\mathrm{DiD}$ analyses using aggregate data cannot provide reliable estimates of the impact of health insurance on mortality.

Finally, several studies focus on Medicaid insurance expansions for particular groups, notably children and pregnant women, and find health gains from these interventions (on pregnant women and newborns, see, for example, Currie and Gruber (1996); on children, see, for example, Dafny and Gruber (2005), Goodman-Bacon (2013), Brown, Kowalski, and Lurie (forthcoming), and Miller and Wherry (2015)).

These studies do not address whether insurance affects health or mortality for other groups of people. In short, experimental and quasi-experimental studies have not reached a consensus on mortality gains from health insurance, tend to focus on only narrow segments of the population, and usually study only short-term effects.

\section{Data, Sample Trimming, and Estimation Methods}

\section{A. DATA SET AND COVARIATES}

We use HRS waves 1 (1992) through 11 (2012). This sample includes individuals who are age 50-61 in 1992; thus all turn 65 and become Medicare-eligible between 4 and 15 years after initial observation. ${ }^{9}$ The full sample is 10,242 individuals surveyed at wave 1 . We

9 For those familiar with the HRS, we include respondents from HRS cohorts 1 and 11, and limit the sample to respondents who are ages 50-61 in 1992. 
exclude 455 people without insurance information and 151 people who lacked data on some covariates at wave 1 . This left a usable sample at wave 1 of 9,636 people, including 7,251 with private insurance (either provided through employment or privately purchased; some also have public insurance), 949 with only public insurance (Medicare, Medicaid, VA, or other government program), and 1,436 uninsured.

We began with the 27 covariates used by MZMA (many are binned; they use 71 variables). We drop several that are likely to be strongly influenced by insurance status (the most obvious are "doctor visit in last 12 months" and "hospital stay in last 12 months"), add granularity to others, and add additional covariates that we considered likely to affect insurance, health, or mortality, and did not impose a large loss in sample size due to missing values. With binning, we use 144 variables.

The extensive covariates in the HRS hopefully allow us to come close to satisfying the core requirement for unbiased estimates, that insurance is as good as randomly assigned, conditional on observed covariates. This is often called "unconfounded assignment" (Imbens and Rubin 2015) or "selection [only] on observables" (SOO). However, it is likely that, to some extent, unobservables still predict both insurance status and mortality, which can be called "selection on unobservables" or SOU. We expect some positive selection (healthier persons are insured), and hence upward-biased estimates of mortality gains from health insurance, when comparing the uninsured with the privately insured, and negative selection when comparing the uninsured to the publicly insured.

Table 1 provides a covariate balance table for selected covariates, for the uninsured versus private controls. As expected, we find large differences on many covariates between uninsured and privately insured individuals. ${ }^{10}$ However, once we use inverse propensity weights to balance the treated and control groups, we obtain good balance on all covariates-all normalized differences are 0.07 or less.

\section{B. SAMPLE TRIMMING}

We use a logit model with the 144 covariates to estimate the probability that an individual is uninsured. Most of the privately insured have a very high likelihood to be insured. In contrast, the propensities for the uninsured are well spread. ${ }^{11}$ This imbalance causes two problems. First, methods for estimating treatment effects that rely on inverse propensity score reweighting (the ATE weights are $1 / p_{i}$ for the treated, where $p_{i}=$ propensity if observation $i$ to be treated; and $\left[1 /\left(1-p_{i}\right)\right]$ for the controls $)$ assign large weights to either treated or control units near the tails of the propensity distribution. This increases the variance of treatment effect estimates. Placing high weights on a limited number of observations can also lead to unstable estimates (e.g., Kang and Schafer 2007).

10 Online Appendix Tables A1 and A2 provide full covariate balance tables for the uninsured versus private and public controls, respectively. Using measures of initial health as covariates is potentially problematic since some could be affected by past or present uninsurance. We therefore also used a specification, which does not control for initial health, and report results in Online Appendix Figure I1. Results are similar to those we report in the text.

11 Online Appendix Table B1 shows the marginal effect of each covariate on the propensity to be treated (uninsured). Online Appendix Figure B1 shows kernel density plots for the propensity to be uninsured. 


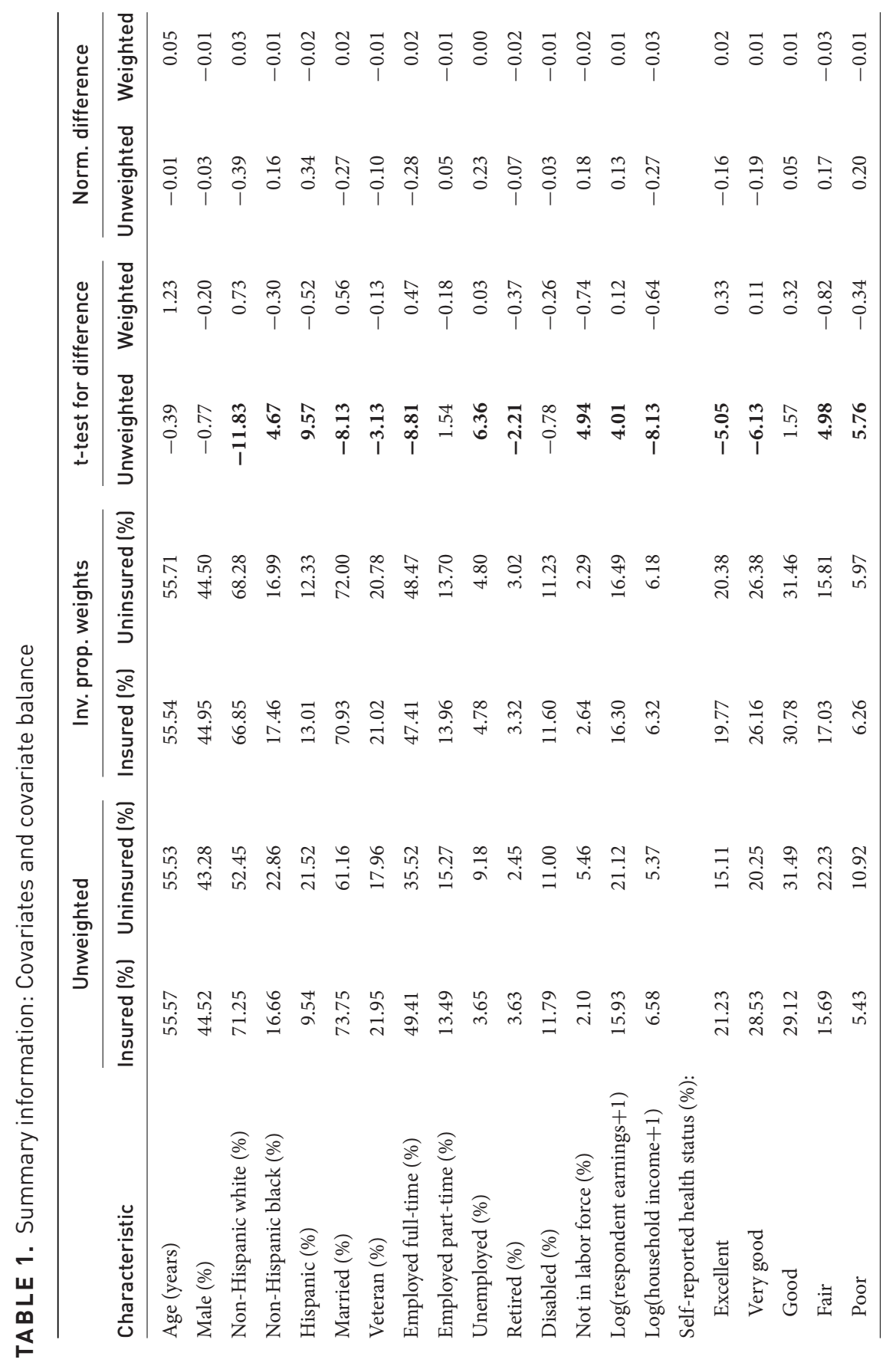




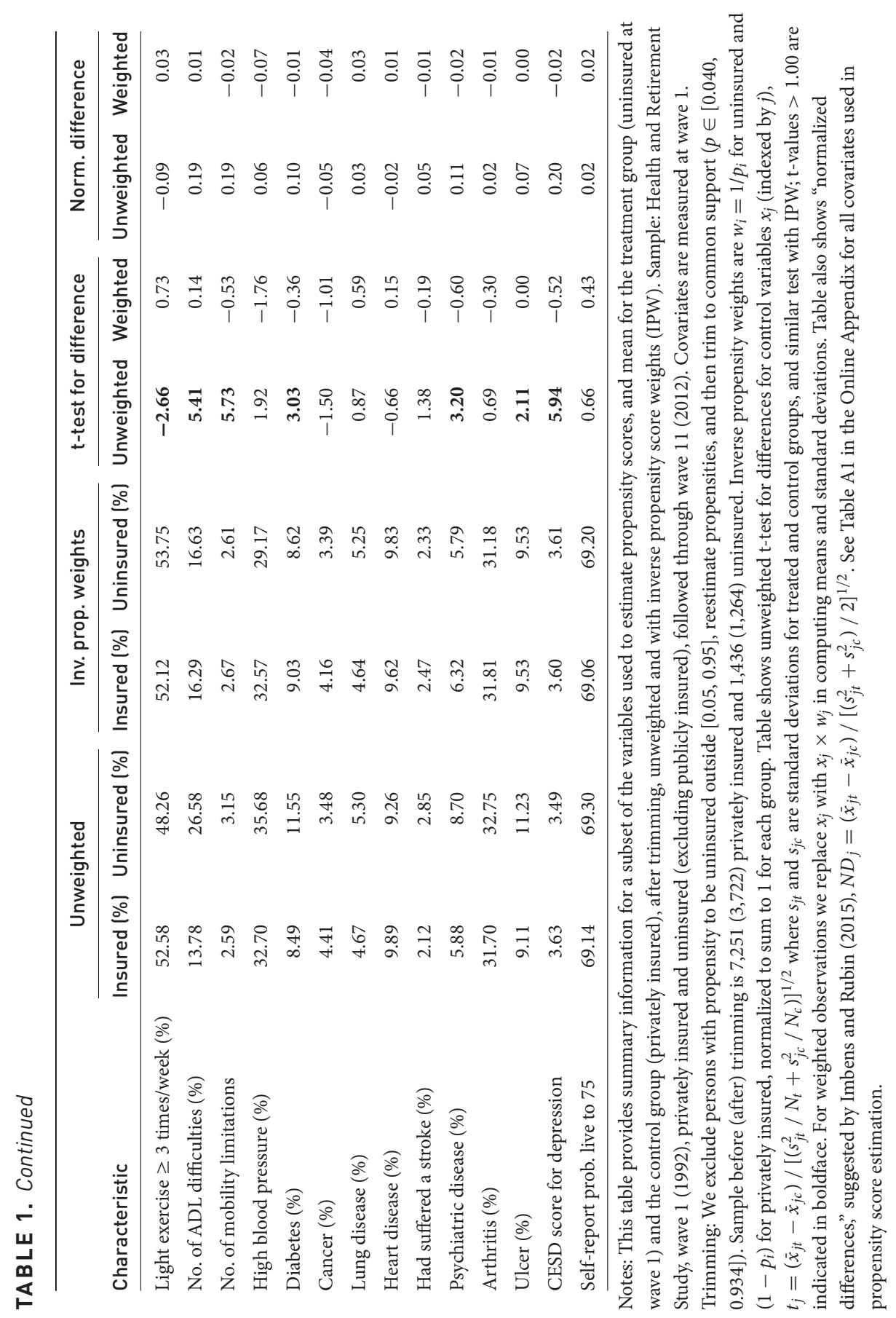


FIGURE 1. Propensities to be uninsured, after trimming
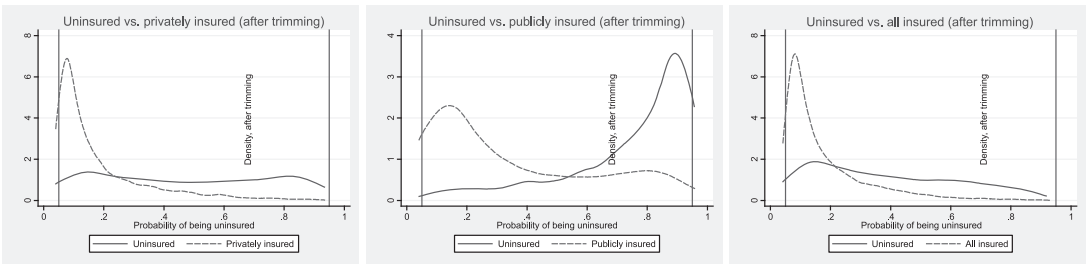

Notes: Kernel densities for probability of being uninsured $\left(p_{i}\right)$ after trimming. Trimming: We exclude persons with propensity to be uninsured outside $[0.05,0.95]$, reestimate propensities, and then trim to common support ( $p \in[0.040,0.934]$ for uninsured vs. privately insured, leaving a sample size of 4,$986 ; p \in[0.041,0.957]$ for uninsured vs. publicly insured, leaving a sample size of 2,018 ; and $p \in[0.041,0.928]$ for uninsured vs. all insured, leaving a sample size of 6,007). Insurance status and covariates are measured at wave 1 . Vertical lines are at $p=0.05$ and $p=0.95$.

Crump et al. (2009) find that trimming observations with high and low propensities will usually reduce variance, despite reduced sample size. We trim the sample so that estimated propensities to be uninsured $p_{i} \in[0.05,0.95]$. We then reestimate propensities on the trimmed sample, then trim to "common support." Covariate balance is improved, but the privately insured mostly have low propensities to be uninsured, while the publicly insured mostly have high propensities. We show kernel densities for the probability of being uninsured, after trimming, separately for the uninsured versus private controls, public controls, and all controls in Figure $1 .{ }^{12}$ In robustness checks, our results are not sensitive to the choice of trimming bounds.

\section{ESTIMATION METHODS}

With MZMA as a partial exception, modern methods for estimating treatment effects in "pure" observational studies, with no experimental or quasi-experimental control group, have not previously been used to study the impact of health insurance on health or mortality. The methods generally rely on inverse propensity score reweighting, subclassification, or matching, often combined with regression and sample trimming. We use the following methods to estimate ATE, ATT, and ATC for the uninsured relative to private controls, to public controls, and to all controls:

(1) "Univariate" analysis using IPW. Difference in weighted mean outcomes using inverse propensity weights (IPW).

(2) Multivariate linear analysis plus IPW. Least squares regression of outcome on uninsurance dummy plus covariates (a linear probability estimate), with IPW. This estimator has the double robustness property noted by Robins and Rotnitzky (2001):

12 For the uninsured versus private controls, trimming modestly reduces the number of uninsured by 12 percent, to 1,313 . The number of privately insured falls by 46 percent, to 3,832 , but most dropped observations were poor matches for the uninsured. 
it will provide unbiased estimates if either the propensity score estimates or the regression adjustments fully address SOU.

(3) Subclassification plus regression. We divide the sample into subclasses with equal numbers of uninsured, based on propensity scores. Within each subclass, we regress the outcome on covariates plus the propensity score, and then combine the subclass estimates.

(4) Matching on log-odds propensities. To estimate ATT, we match each treated person $i$ to the control person $j$ with the closest value of $\ln \left(p_{i} /\left(1-p_{i}\right)\right)$, using one insured match for each uninsured, with replacement.

(5) OLS regression. OLS (linear probability model) estimates of mortality on an uninsurance dummy plus covariates. OLS assumes homogeneous treatment effects and therefore provides only an ATE estimate.

We report results from methods (1) and (2) in the text. We find similar results with the remaining methods, and report those results in the Online Appendix. ${ }^{13}$

\section{WHAT EFFECT ARE WE MEASURING?}

We measure the marginal effect of health insurance on health and mortality, against the backdrop of an array of interventions in health care and health insurance markets. We measure the effect of health insurance, not health care. Uninsured people can obtain care in a variety of ways, including emergency care under EMTALA (Emergency Medical Treatment and Active Labor Act); charity care from public or nonprofit hospitals or clinics; workers' compensation for on-the-job accidents; and auto insurance for injuries in auto accidents. Many people can purchase some health care without insurance, using either savings or borrowing. Many vulnerable populations are eligible for Medicare or Medicaid insurance. Thus the health-care safety net has holes, but catches many people and health conditions, and thus reduces the marginal gains from insuring the currently uninsured (Hall 2011).

We measure uninsurance at wave 1 , in $1992 .{ }^{14}$ Implicitly, we treat uninsurance at initial observation in 1992 as a proxy for a longer history of uninsurance or irregular insurance, both past and future. Uninsurance, however, is often temporary. We show the proportion of the initially uninsured who are also uninsured in each of the later waves in Figure 2. Figure 2 contains separate lines for age cohorts. The age 60-61 cohort is partly Medicareeligible after four years (wave 3 ) and fully eligible after six years; the age 58-59 cohort is

13 In unreported robustness checks, we find similar results with several other methods, including KaplanMeier survival analysis, and the Gutman and Rubin (2013) MITSS (multiple imputation with two splines within subclasses) approach. We also attempted nearest-neighbor matching (Abadie and Imbens 2012), but the estimates were sensitive to exactly how we defined our sample, which suggests that we may be "overfitting" by matching on too many covariates.

14 The HRS asks respondents only: "Are you currently covered by [health] insurance?" 
FIGURE 2. Uninsurance status over time

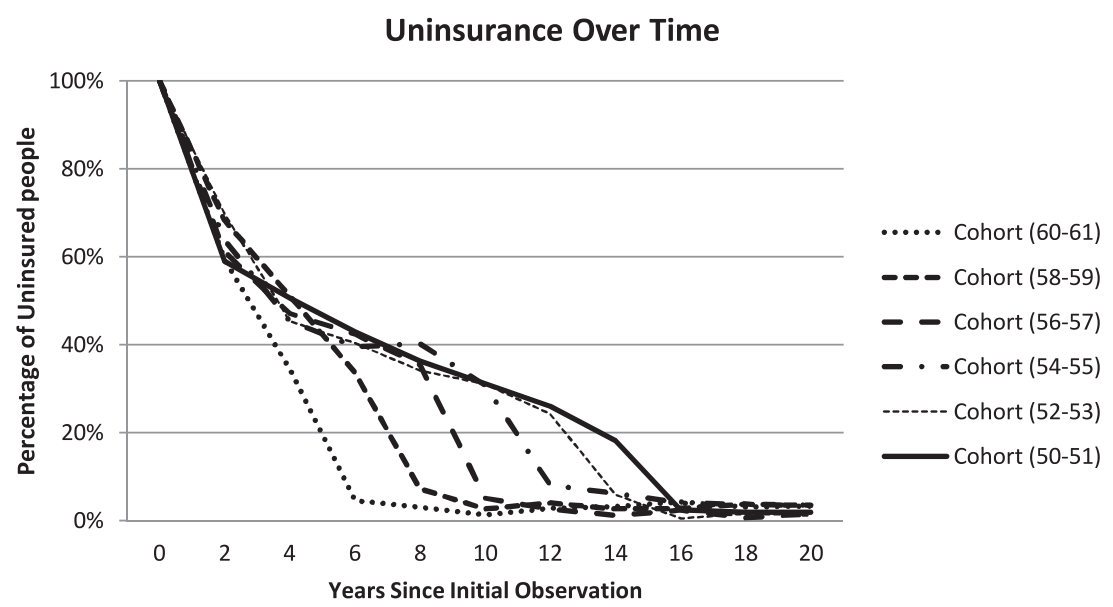

Notes: Fraction of uninsured persons at initial observation in 1992, by age cohort in 1992, who were uninsured in 1992 and in the indicated subsequent waves. Percentage uninsured at year 4 (wave 3) includes persons who were insured in wave 2, and similar for later waves. Online Appendix, Figure $\mathrm{C} 1$, provides a similar figure showing the proportion of each age cohort who were continuously uninsured through each wave. Uninsurance rate drops effectively to zero as each cohort reaches Medicare age (age 65). Sample: $n=1,440$ uninsured persons included in Health and Retirement Study, wave 1 (1992), initial age 50-61, uninsured in 1992. Denominator for each observation wave is persons still alive at that time. Waves are two years apart. A respondent is uninsured if she reports not being currently covered by health insurance at the time of the survey.

fully eligible after eight years, and so on. Among those under 65, roughly 60 percent are uninsured after two years, and about half are uninsured after four years. ${ }^{15}$

We cannot use the HRS to directly assess whether long-term uninsurance has longterm health effects-the number of long-term uninsured is too small. We can, however, make some progress on this issue by comparing the twice uninsured (at wave 1 in 1992 and wave 2 in 1994) with the twice insured (in both 1992 and 1994), and to the once uninsured (in 1992 or 1994, but not both). The mortality trajectories for the twice uninsured, versus the once uninsured, or the twice insured are similar to those in which we measure uninsurance only in 1992 (Figure 4). In unreported results, we confirm that the health of the once uninsured (in 1992 or 1994 but not both) is similar to the health of the twice uninsured. These results suggest that uninsurance at initial observation in 1992 is likely to be a reasonable proxy for longer-term uninsurance.

15 Some of the initially uninsured cycle in and out of having health insurance. In Online Appendix Figure $\mathrm{C}$, we show the proportion of the initially insured in each age cohort that remains continuously uninsured through each later wave. 


\section{Impact of Uninsurance on Mortality over Time}

In this section, mortality, measured at each of waves $2-11$, is the dependent variable. A positive treatment effect implies that the uninsured die sooner than the insured. We focus first on mortality because mortality has been the most studied outcome in the literature. We present treatment effect estimates for mortality using a number of different methods.

\section{A. UNIVARIATE IPW ESTIMATE}

As an initial step, Table 2 reports the raw mortality rate for the uninsured versus each control group, both unweighted and using ATT weights, for selected years. ${ }^{16}$ Consider first the upper bound estimate, obtained by comparing the uninsured with the privately insured (panel A). The uninsured have higher mortality in each wave, and the gap increases over time. However, once we apply inverse propensity weights, the gaps shrink and most are statistically insignificant. One can also construct a crude hazard rate by taking a ratio of the mortality rates of the two groups. Let $f_{t}^{\text {unins }}(A T T)$ be the fraction of uninsured who have died by year $t$, using ATT weights, and similarly for the insured. A univariate hazard rate (uni-h-r) is the following:

$$
\begin{aligned}
& \text { uni-h-r } r_{t}^{\text {unins/priv }}(A T T)=\frac{f_{t}^{\text {unins }}(A T T)}{f_{t}^{\text {priv }}(A T T)} ; \text { for example, } \\
& \text { uni-h-r } r_{8}^{\text {unins/priv }}(A T T)=\frac{0.1136}{0.0990}=1.15
\end{aligned}
$$

That is, after eight years the hazard rate is 1.15 . At year 20 , the univariate hazard rate at year 20 is similar, at 1.12 .

Consider next the lower bound estimate, from comparing the uninsured with the publicly insured (panel B). In earlier waves, the publicly insured die sooner than the uninsured, even after using IPW. However, the differences between groups are not statistically significant and shrink in later waves. At year 20, the difference in mortality is 1.47 percent $(t=$ 0.36 ) and the hazard rate is close to one (0.97), implying neither an economically important nor a statistically significant difference between the two groups. These results, taken as a whole, are consistent with modest positive selection for the privately insured versus the uninsured (the privately insured are healthier for unobserved reasons), which affects mortality only in later waves; and modest negative selection for the publicly insured versus the uninsured, which shrinks in later waves. This suggests that these selection effects might roughly offset each other if we compare the uninsured with all insured.

We next compare the uninsured to "all insured" (panel C). We have 1,335 uninsured and 4,672 insured after trimming, of which 3,986 (85 percent) are privately insured. Thus, the "all insured" controls are weighted toward the privately insured. With ATT weights, mortality is slightly, but not statistically significantly, lower for the uninsured through 16 years after initial observation. Uninsured mortality rises in years $18-20$, relative to the

16 We present results for all waves and results with ATC weights in the Online Appendix, Table D1. 


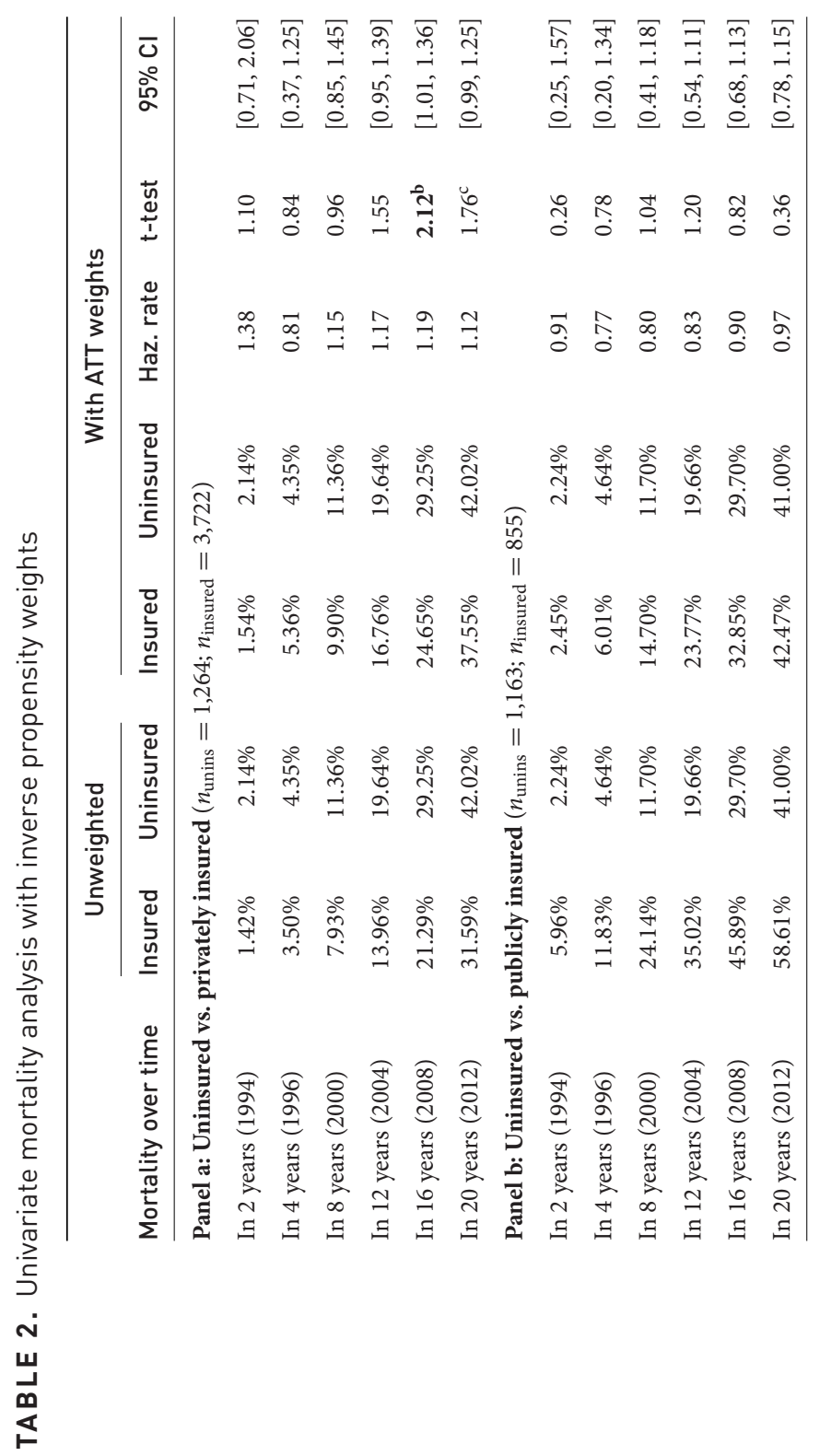




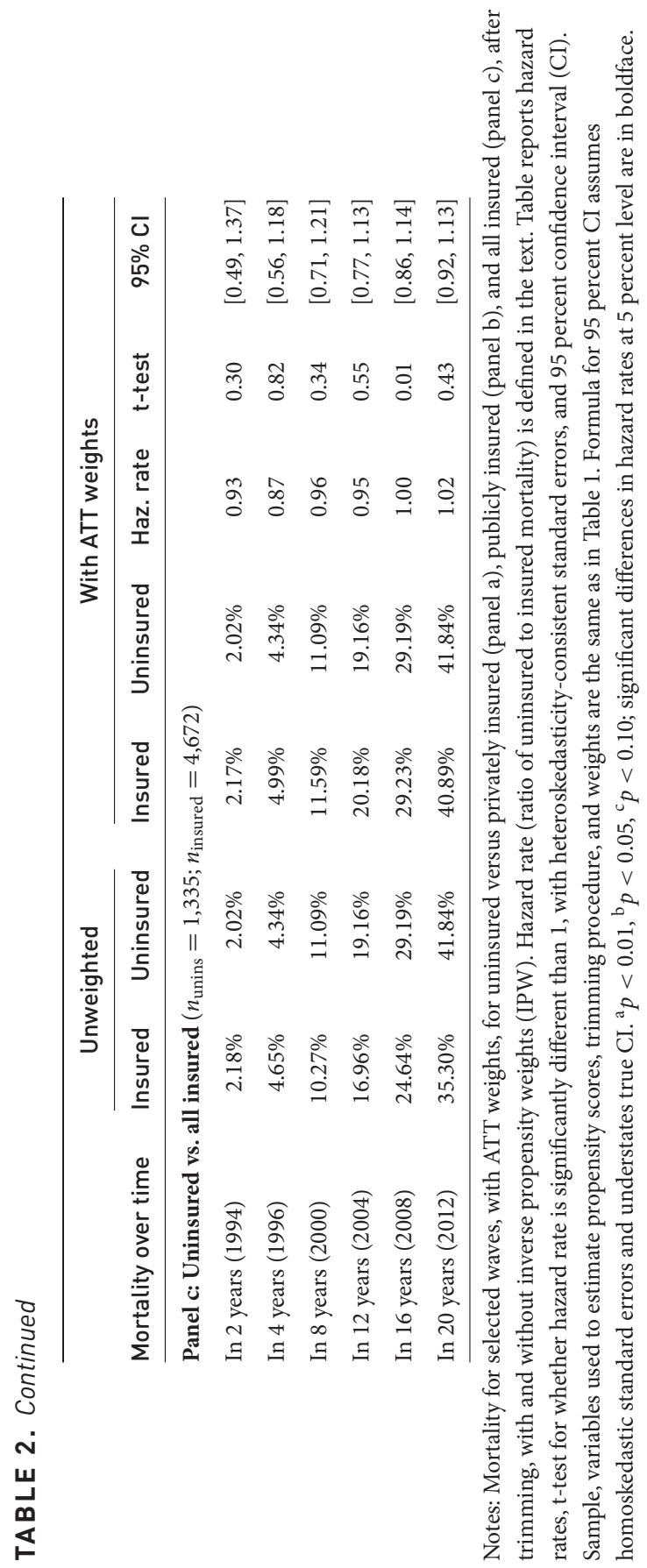


FIGURE 3. Mortality of uninsured, relative to insured (linear analysis, inverse propensity weights)

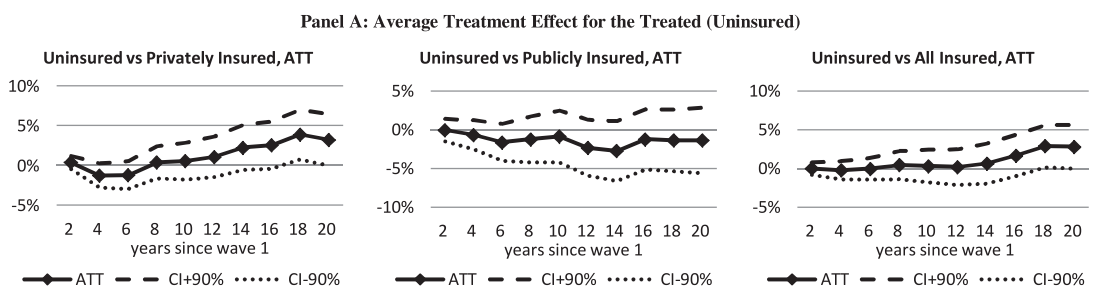

Panel B: Average Treatment Effect for the Controls (Insured)
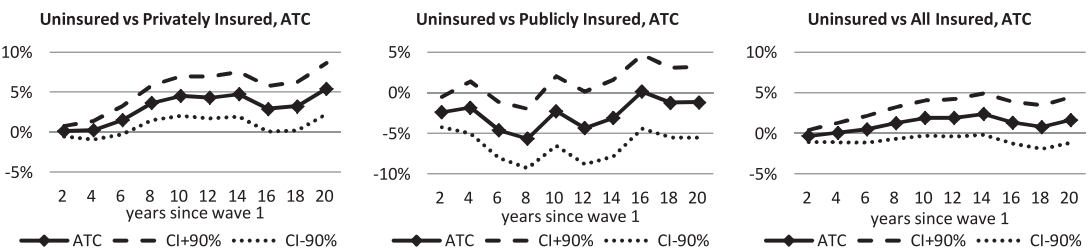

Notes: ATT and ATC estimates from linear regression of mortality on treatment (uninsurance) dummy and covariates, using inverse propensity weights. ATT weights are 1 for uninsured; $p_{i} /\left(1-p_{i}\right)$ for insured; ATC weights are $\left(1-p_{i}\right) / p_{i}$ for uninsured; 1 for insured. Graph shows point estimates and 90 percent CI. Horizontal axis shows years since wave 1. Sample is HRS wave 1, after trimming. See Figure 1 for trimming process and sample sizes. Insurance status and covariates are measured at wave 1 (year 0). Covariates are listed in Table A1 in the Online Appendix.

insured, but the difference remains insignificant. At 20 years, the uninsured have 0.96 percent higher mortality $(t=0.43)$. The associated hazard rate is 1.02 , only slightly greater than one.

We present ATC estimates in the Online Appendix, Table D1. The hazard rates are generally larger than the ATT estimates, although the difference shrinks in later waves. ${ }^{17}$ These differences provide evidence of treatment effect heterogeneity and confirm the importance of examining ATT and ATC separately. The larger ATC estimates suggest that any mortality gains from insurance are larger for those who have insurance-in effect suggesting that those who will gain from being insured often find a way to obtain insurance.

\section{B. LINEAR REGRESSION PLUS IPW}

We turn next to multivariate estimates that combine IPW with second-stage regression of the outcome variable on covariates. We present ATT and ATC estimates in Figure 3. We present six graphs; each shows point estimates and a 90 percent confidence interval (CI) for each wave. Consider first the leftmost set of graphs, in which we compare the uninsured with private controls. The ATT estimate is near zero through 12 years, but then

17 After 10 years, the ATC hazard rate versus all insured is 1.14, versus an ATT rate of 0.95 . But after 20 years the ATC hazard rate is 1.06, only slightly above the ATT rate of 1.02. 
gradually increases and becomes statistically significant after 18 years (coeff. $=0.039 ; \mathrm{t}=$ 2.06) before falling to $0.032(t=1.65)$ in year 20 .

An increasing effect of health insurance over time is possible under unconfounded assignment, but for our sample, this would be an odd pattern. Our prior was that any treatment effect would likely weaken once most of the sample reached Medicare age. By year 10 the mean age for our sample is 66. Instead the ATT estimate increases well after most of the sample has reached Medicare age. This rise could be due to the gradual emergence of health problems that could have been prevented by earlier preventive care, but it could also reflect the slow emergence of an impact on mortality of selection on unobservables.

The uninsured have lower mortality in all waves than the publicly insured (Figure 3, middle graphs), but the ATT point estimates are small in magnitude and never statistically significant. The ATC estimates bounce a fair amount from wave to wave, which we view as suggesting an imperfect specification.

We provide our central estimate, from comparing the uninsured with all insured, in the right-hand charts in Figure 3. The ATT estimates are close to zero though 14 years, then rise to 0.028 by year 20 , but remain insignificant $(t=1.64)$. These estimates support, at most, a modest, slow-to-emerge mortality benefit from insurance for the currently uninsured, with slowly emerging SOU as an alternate explanation.

We can also use the regression coefficients to compute a regression-based hazard rate. Let $\beta_{t}^{\text {unins }}(A T T)$ be the regression coefficient for uninsured mortality at year $t$ and $f_{t}^{\text {insured }}(A T T)$ be the fraction of insured who have died by year $t$, using ATT weights. A regression-based hazard rate is then the following:

$$
r e g-h-r_{t}^{\text {unins }}(A T T)=\frac{\beta_{t}^{\text {unins }}(A T T)}{f_{t}^{\text {insured }}(A T T)}
$$

The 10-year ATT hazard ratio estimate versus all insured is 1.02 (95 percent $\mathrm{CI}=[0.87$, 1.17]); this rises after 20 years to 1.07 (95 percent $C I=[0.99,1.15]$ ).

In broad measure, the multivariate results, using IPW plus regression, are similar to the univariate results using IPW alone. The ATT estimates versus private controls and versus public controls are closer to zero when we include covariates. The univariate and multivariate ATT estimates versus all controls are similar.

\section{UPPER AND LOWER BOUNDS}

We can use the information in Figure 3 to develop rough upper and lower bounds on our central ATT estimate. We expect positive selection for the uninsured versus private controls, and negative selection for the uninsured versus public controls. We therefore define an upper bound as the ATT estimate versus private controls, plus one standard deviation, and a lower bound as the ATT estimate versus public controls, minus one standard deviation. ${ }^{18}$

18 We present the central estimate, plus these bounds, in Online Appendix Figure E1. The use of two control groups, with opposite selection biases, to bound treatment effects was proposed by Rosenbaum (1987). 
FIGURE 4. Mortality of twice uninsured, relative to twice insured and once insured (linear analysis with IPW)
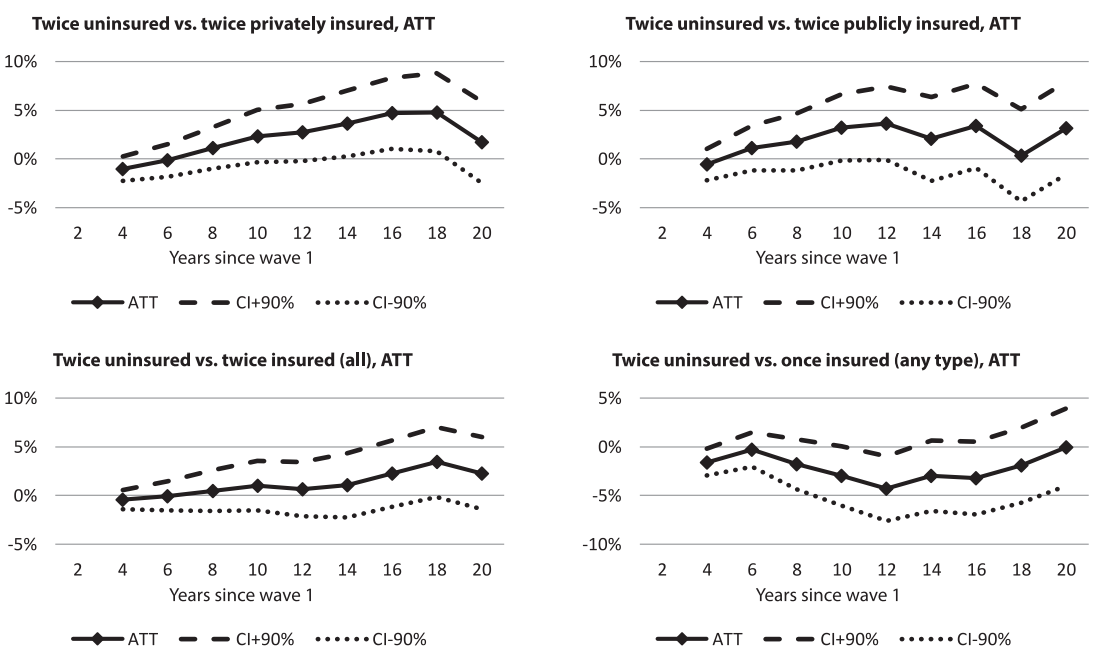

Notes: ATT estimates from linear regression with IPW of mortality on twice uninsured treatment dummy (uninsured at waves 1 and 2) and covariates. Graphs show point estimates and 90 percent CI. Sample is HRS wave 1, excluding persons who died by wave 2. Trimming: We exclude persons with propensity to be twice uninsured outside $[0.05,0.95]$, reestimate propensities, and then trim to common support. Sample for twice uninsured (treated) vs. twice privately insured (control): $n_{t}=$ 771; $n_{c}=2,092$; vs. twice publicly insured: $n_{t}=629 ; n_{c}=607$; vs. all twice insured: $n_{t}=809 ; n_{c}=$ 2,682; vs. once insured: $n_{t}=894 ; n_{c}=867$. Covariates are measured at wave 1 and are listed in Table A1 in the Online Appendix. Horizontal axis shows years since wave 1.

These bounds also generate bounds on hazard rates: after 10 years, these bounds are $[0.85,1.14]$; after 20 years, the bounds are [0.91, 1.14]. The upper bound estimate is consistent with an "economically" important effect of health insurance on mortality. At the same time, it is far below prior point estimates in the literature, such as the 1.43 estimate after eight years presented by MZMA.

\section{LONGER-TERM UNINSURANCE}

Uninsurance is often temporary (Figure 2). Uninsurance in 1992 is thus an imperfect proxy for being uninsured for a sustained period of time. Would there be a larger effect of uninsurance on health for persons who are more regularly uninsured? We provide some evidence on that question in Figure 4. We present ATT estimates, using IPW plus regression, in which we compare the twice uninsured (in both 1992 and 1994) to the twice insured and to the once uninsured (insured in 1992 or 1994 but not both).

The extra mortality of the twice uninsured, versus the twice privately insured, is near zero at years $4-8$, tilts up to around 5 percent at years $14-16$, before falling to 2 percent at year 20 (Figure 4, top left chart). The confidence intervals are larger than in prior figures because of a smaller sample. When we compare the twice uninsured with the twice publicly 
insured, the twice uninsured have somewhat higher mortality, but all point estimates are insignificant.

The bottom left chart shows ATT estimates for the twice uninsured versus the twice insured (any type of insurance). The estimates are similar to those for the once uninsured versus all insured in Figure 3-small through year 14, with somewhat higher, but still insignificant, estimates in years 16-20. Much as for the once insured, this late rise in mortality could reflect either a delayed effect of insurance on mortality or a delayed emergence of SOU.

Finally, the bottom right chart in Figure 4 provides ATT estimates for the twice uninsured versus the once uninsured. The point estimates are generally negative, consistent with the twice uninsured being unobservably somewhat healthier than the once uninsured. Thus, while uninsurance at wave 1 is an imperfect proxy for longer-term uninsurance or irregular insurance, we cannot meaningfully improve on this proxy by using uninsurance at successive waves to define the treatment group.

\section{Other Outcomes: Health-Care Utilization and Health}

We turn in this part to whether uninsurance predicts health-care utilization (Section A), or health outcomes other than mortality (Section B). We present ATT estimates using IPW plus linear regression. ATC estimates and estimates using other methods are similar.

\section{A. EFFECT OF UNINSURANCE ON HEALTH-CARE UTILIZATION}

The uninsured, if provided with insurance, are known to consume more health-care services. We provide additional evidence on this issue below. We also address a less-studied question: will the previously uninsured consume more or less health care than the previously insured, once both groups are insured at age 65 ? The only prior study that addresses this question is a separate McWilliams et al. (2007b) paper. The authors use the HRS, discard the publicly insured, and compare the uninsured to persons with private insurance for at least three waves before turning 65 . They report that previously uninsured persons with hypertension, diabetes, heart disease, or stroke have more doctor visits and hospitalizations after age 65 than privately insured controls. Previously uninsured persons without these conditions continue to have fewer visits and hospitalizations than their controls.

We present ATT estimates for the uninsured versus all insured, for six normalized measures of health-care utilization (Figure 5). ${ }^{19}$ In earlier waves, the uninsured use somewhat fewer health-care services. The estimated effects rise in later waves, as the initially uninsured become Medicare-eligible, but generally remain negative.

Consider the top left chart, for hospital admission. The outcome is a dummy variable for whether the respondent was hospitalized in the last two years. The uninsured are 0.16 standard deviations less likely to be admitted to a hospital than the insured in 1992. After that, hospitalization rates for the initially uninsured rise and roughly match those for the initially insured in years 10-16, but then drop again in years 18-20; we have no good explanation for this drop. The bottom left chart, for days in the hospital, is generally similar.

19 We normalize all measures to mean 0 , standard deviation $\sigma=1$. 
FIGURE 5. Health-care utilization, ATT (linear analysis with IPW)

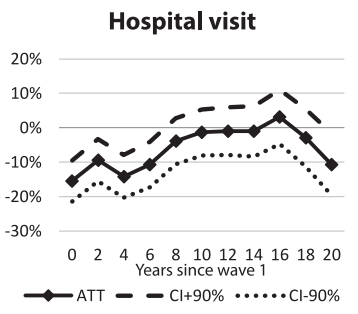

No. of nights at a hospital

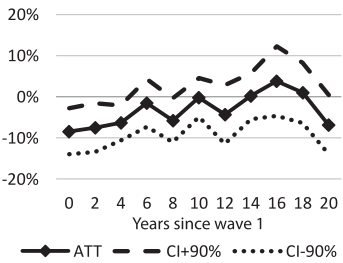

Doctor visit

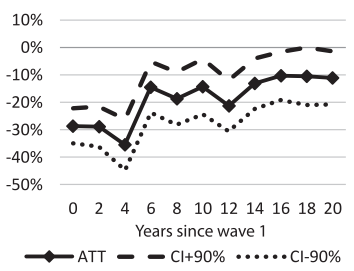

Doctor visit

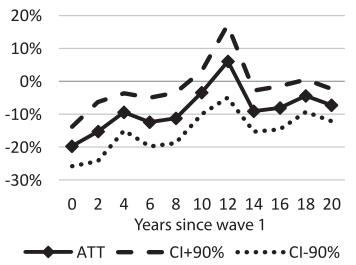

Were drugs prescribed?

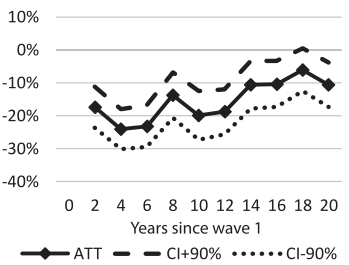

Didn't take prescribed drugs, fin'l reason

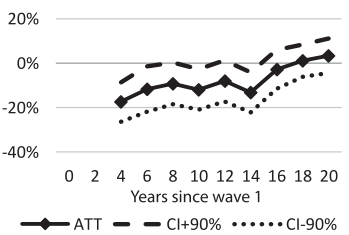

Notes: ATT estimates from linear regression with IPW of indicated measures of health-care utilization for each wave on treatment (uninsurance at wave 1) dummy and covariates. We normalize each measure in each wave to mean $0, \sigma=1$. The control group is all insured persons. The graphs show point estimates (as percentages of a standard deviation) and 90 percent CI. Sample, trimming, covariates, and weights are the same as for Figure 3. Outcomes are whether the respondent stayed in a hospital during the last two years; whether the respondent visited a doctor during the last two years; whether the respondent has been prescribed any drug; how many nights the respondent spent in a hospital during the last two years; how many times the respondent visited a doctor during the last two years; and whether the respondent did not take prescribed drugs for financial reasons (multiplied by -1 so positive values show taking prescribed drugs). Horizontal axis is years since wave 1. Data on whether drugs were prescribed are available from wave 2; data on whether prescriptions went unfilled for financial reasons are available from wave 3 .

Consider next the two middle charts, for doctor visits. In the early waves, the uninsured are much less likely to have seen a doctor in the last two years, and have fewer average visits. The "visited a doctor" point estimates rise toward zero beginning in year 6, but remain negative for all years.

The top right chart reports the effect of being uninsured on whether any drugs were prescribed in the last two years. The uninsured are substantially less likely to have received a prescription in all waves, even after most reach Medicare age. Conditional on having a prescription, they are more likely to have not filled the prescription for financial reasons in early waves, but this effect disappears by year 16 (bottom right chart).

We thus find consistent evidence that, in the early waves, the uninsured receive less care. This effect moderates but, for most measures, persists after they reach Medicare age.

Overall, as the initially uninsured become Medicare-eligible, they approach the initially insured in health-care use, but no more. There is no rebound effect, in which those 
uninsured before age 65 receive more health care once insured than those who were insured all along. These results do not rule out a rebound for subgroups with particular diseases, as found by McWilliams et al. (2007b).

The real but limited differences in care intensity reinforce one explanation for a small estimated effect of insurance on mortality and health-we are measuring the marginal effect of health insurance on health care and thus on health. The uninsured still obtain a fair amount of health care. Much of the additional care they would receive if insured could provide limited marginal benefit (Fuchs 2004).

\section{B. EFFECT OF UNINSURANCE ON HEALTH AND DISABILITY}

We turn next to whether uninsurance predicts health outcomes other than death. A caveat: we observe health only for those who are still alive. If insurance predicts higher survival, but the extra survivors tend to be in poor health, estimates of the health impact of insurance will be biased toward poorer health. As we show above, however, these mortality effects appear to be small.

No prior study of the impact of health insurance on health outcomes uses a matched, or propensity score reweighted, sample of insured and uninsured. McWilliams et al. (2007a) use the HRS and find post-age-65 improvements in several health measures for previously uninsured persons with cardiovascular disease or diabetes, relative to the previously insured, but insignificant effects for other measures. However, instead of removing the deceased from their sample, the authors impute poor health to them. This imputation could drive their results.

We use IPW plus linear regression to estimate the ATT for the uninsured versus all insured, for six normalized measures of health (mean $=0$; standard deviation $=1$, coded so positive values indicate more disease/worse health): self-reported overall health; number of difficulties with five activities of daily living (ADLs: taking a bath, dressing, eating, getting out of bed, walking across the room); heart disease; stroke; diabetes; and depression (Figure 6). ${ }^{20}$

An initial question is whether the health of the uninsured deteriorates relative to the insured after wave 1. It does not. A second question is whether the health of the initially uninsured improves relative to the previously insured in later waves, as the uninsured reach age 65. Again, it does not. The ATT estimates are sometimes negative (suggesting that health improves for the uninsured), sometimes positive, rarely statistically significant, and bounce around a fair amount. To give one example, with IPW alone, average selfreported health status for the uninsured in 1992, on a 1 (excellent) to 5 (poor) scale, is 2.96, versus 3.02 for the insured. Ten years later, the averages are again close, at 3.23 for the initially uninsured versus 3.20 for the initially insured. Overall, there is no evidence that initial uninsurance predicts changes in future health, either before or after Medicare age.

20 We balance treated and controls on most of these measures, so ATT estimates at year 0 are near zero and are not reported in Figure 6. In unreported robustness checks, we find similar results using other methods. We present results for six additional health measures in Online Appendix Figure G1. 
FIGURE 6. Health outcomes, ATT (linear analysis, inverse propensity weights)

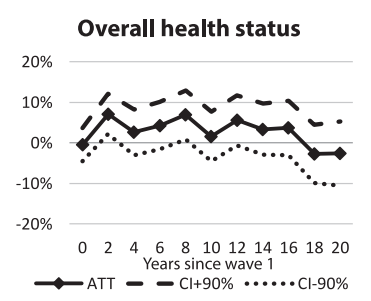

Limits on ADLs

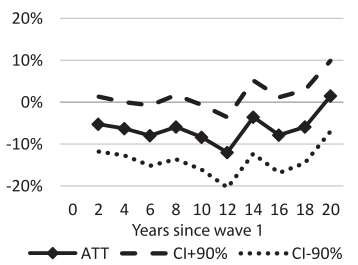

Heart disease

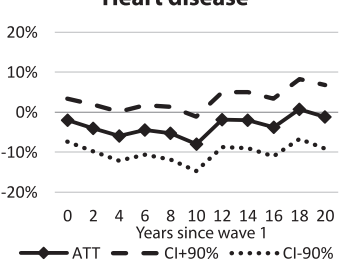

Stroke

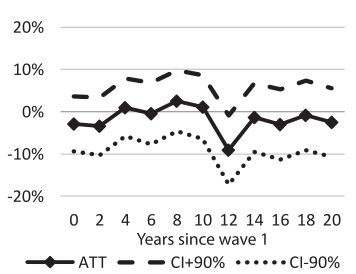

Diabetes

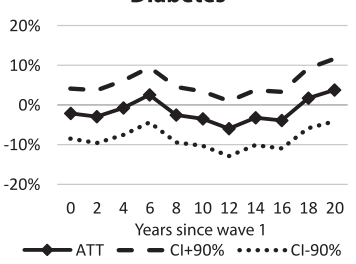

Depression

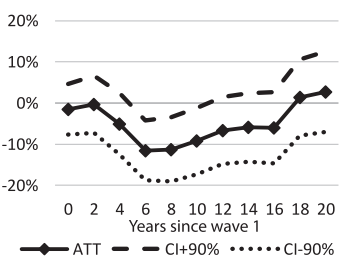

Notes: ATT estimates from linear regression with IPW of indicated measures of health status for each wave on treatment (uninsurance at wave 1) dummy and covariates. We normalize each measure in each wave to mean $=0, \sigma=1$; positive values for health status indicate worse health. The control group is all insured persons. The graphs show point estimates (as percentages of a standard deviation) and 90 percent CI. Sample, trimming, covariates, and weights are the same as for Figure 3, except that we omit the dependent variable as a covariate. Outcomes are self-reported health status $(1=$ excellent to $5=$ poor $)$, number of difficulties in five activities of daily living (taking a bath, dressing, eating, getting out of bed, walking across the room (0-5)), and whether the respondent has ever had heart disease, stroke, diabetes, or depression.

We discuss here what one can say about relative health changes, at the risk of overinterpreting insignificant results. The HRS asks respondents to rate their health from $1=$ excellent to $5=$ poor. The uninsured tend to report being in slightly worse health than the insured in the early waves, and similar health in later waves. There is no evidence of deterioration over time in health for the uninsured. The uninsured report somewhat fewer difficulties with ADLs. Heart disease and stroke rates are similar. The uninsured tend to have lower diabetes and depression rates. These lower rates could reflect less diagnosis rather than less disease, but if so, one might expect rates for the uninsured to rise after they reach Medicare age. Figure 6 shows no evidence of such a trend. The one measure on which the Oregon Medicaid experiment showed a significant near-term impact of health insurance on health was that the newly Medicaid-insured were less likely to be depressed (Baicker et al. 2013; see also Polsky et al. 2009). We do not confirm that result for our sample. Across these measures, and the additional health measures we report in the Online Appendix, Figure G1, the broad picture is of similar changes in health for the uninsured and insured. ${ }^{21}$

21 The weak effect of insurance on health ameliorates one limitation of our research design: We estimate propensities to be insured based on covariates measured at wave 1. If those covariates are affected by past uninsurance (which is correlated with uninsurance at wave 1), this could bias our estimates. 
In unreported results, we estimate health for the uninsured separately versus private controls and public controls. Consistent with our results for mortality, these results for health suggest modest selection effects: positive selection (better health) for the privately insured, and negative selection for the publicly insured. Neither comparison suggests that access to health insurance significantly affects health.

\section{Discussion}

\section{A. SELECTION BIAS AND CREDIBLE TREATMENT EFFECT ESTIMATES}

We do not show that health insurance has no effect on health or mortality. We do show that (1) there is only mild evidence from the HRS that health insurance importantly affects either mortality or health while alive; and (2) prior studies that found large positive benefits from health insurance are flawed.

Selection effects pose a core challenge for any pure observational study. We believe we were able to reduce the magnitude of these effects by fully exploiting the rich HRS data set, and taking great care with covariates and estimation methods. Our central estimates, for the uninsured versus all insured, should be more reliable than estimates relative to private controls alone or public controls alone. Those estimates are small and generally statistically insignificant. Our upper bound estimates for the effect of uninsurance on mortality, relative to private controls, are well below the point estimates reported in most prior studies. We also provide estimated treatment effects over time since initial treatment, and estimate separate treatment effects for the uninsured and the insured.

\section{B. IS A NEAR-ZERO EFFECT OF INSURANCE ON HEALTH AND MORTALITY CREDIBLE?}

Could our central ATT estimates, of a near-zero effect of initial uninsurance on mortality through year 14, and small positive estimates after that, be "truth"? In our judgment, yes, for several reasons.

We expect that health insurance affects health mainly through access to health care, which in turn can affect health and mortality. We find, consistent with other studies, that the insured consume more health-care resources, but the differences are not dramatic. The additional marginal care that the insured receive may improve health in some specific situations, ${ }^{22}$ but worsen health, or make little difference, in others. Examples abound in which additional care (or more expensive care, when a cheaper alternative is available) is neutral or harmful for health. Insured women with health insurance were more likely to receive hormone-replacement therapy in the 1990s, which raised breast cancer rates without reducing heart disease rates. Insured men are more likely to receive prostate cancer screening and follow-up testing and treatment, with no overall benefit; the testing alone carries substantial mortality risk from infection. People with health insurance are more likely to receive CT scans; the radiation exposure predicts higher future cancer rates. We

22 See Wu and Shen (2011), higher heart attack mortality at hospitals that face larger Medicare reimbursement cuts; and Doyle (2005), higher mortality for uninsured following car accidents. 
also know that areas with higher Medicare spending do not achieve better outcomes (e.g., Skinner 2012). Thus, even if health care is highly valuable on average, extra care at the margin may be of modest value (Chandra and Skinner 2012).

A further explanation for small effects could be that the United States has a respectable, if imperfect, safety net already in place. We insure the elderly, veterans, the disabled, and, in part, the very poor. We provide emergency care to everyone. Public clinics exist, if not everywhere. Many of the uninsured may have some access to savings or to borrowing to finance needed care. Bankruptcy provides a safety valve if borrowing exceeds ability to repay. $^{23}$

\section{BOUNDS ON TREATMENT EFFECTS}

A common strategy, when selection effects are possible, is to provide bounds on the likely estimates. Several approaches exist, ranging from ultraconservative Manski bounds, which always include zero (Manski 1990), to conservative Rosenbaum bounds (Rosenbaum 2009), to the somewhat less conservative bounds proposed by Hosman, Hansen, and Holland (2010) and Altonji, Elder, and Taber (2005); see also Oster (2016). Our approach is distinct from each of these. We use two different control groups, for which selection effects likely point in opposite directions, and estimate ATT for both groups, which likely bound the true causal effect. ${ }^{24}$

Are we justified in viewing estimates versus the privately insured as an upper bound on the true effects? If most private insurance was individually purchased, one would worry that the uninsured might be unobservably healthier, which could explain why they did not buy insurance. However, this concern is offset by several factors. First, most people obtain private insurance as a byproduct of being employed (which may predict unobserved good health), rather than purchasing it directly. Second, insurers may seek to screen out the less healthy by charging higher premiums, by excluding preexisting conditions, or by declining coverage. We do know that the privately insured are observably healthier than their uninsured counterparts. In unreported results, the observed health of the privately insured who purchase health insurance is similar to those with employer-provided insurance.

\section{TREATMENT EFFECTS OVER TIME}

Prior studies of the impact of uninsurance on mortality or health generally provide estimates at a single point in time. For example, MZMA estimate mortality eight years after initial uninsurance. Most also have an observation period far shorter than the 20 years we

23 Another possible explanation for small effects is moral hazard-perhaps insured people are less careful about their health. Prior evidence on whether health insurance induces significant moral hazard is mixed; compare Bhattacharya et al. (2011) with Courtemanche and Zapata (2014). We balance the insured and uninsured on initial weight and health behaviors such as smoking, drinking, and exercise. In unreported results, the two groups follow similar time trends for these variables over our sample period.

24 This approach was proposed by Rosenbaum (1987); see also Rosenbaum (2010, \$ 8.2). Rosenbaum generously attributes the idea to an essay by Campbell (1969), who mentions "bracketing" a treatment effect in a true experiment by using variation in observables. We see this as a different question. Shadish, Cook, and Campbell $(2002,123-24)$ discuss using two different control groups to obtain bounds on treatment effects and cite both Rosenbaum and Campbell. 
have available. In our view, there is much to be learned from time series estimates. First, our near-zero central estimate through year 14 gains credibility because it is consistent across waves.

Second, variation over time sheds light on the nature of both treatment effects and selection effects. We find evidence for a slow, gradual emergence of a treatment effect, a selection effect, or both in the later waves-although a treatment effect and SOU could also offset each other in earlier waves. A theory of how uninsurance affects long-run health or mortality, and for whom, must address that time pattern.

\section{E. LONGER-TERM UNINSURANCE}

We treat uninsurance at wave 1 as a proxy for longer-run uninsurance or irregular insurance. Could long-run uninsurance have larger health consequences than irregular insurance? We cannot directly assess this question, because there are too few persons in our sample who are uninsured across multiple consecutive waves to allow us to reliably estimate treatment effects. But we do estimate treatment effects for the twice uninsured versus the twice insured. Those estimates are similar to those for the initially uninsured versus the initially insured. Moreover, a comparison of the twice uninsured to the once uninsured provided no reason to believe that the twice uninsured are unobservably sicker than the once uninsured.

\section{Conclusion}

We provide both central estimates and upper and lower bounds for the long-run effects of health insurance on health and mortality. Our central estimates for mortality are small and statistically indistinguishable from zero through 14 years after initial observation, and our upper bounds are well below the point estimates from prior observational studies. Our central estimates for the effect of uninsurance on health while alive are also small and statistically insignificant. Our estimates are almost surely affected by selection into insurance status. Our goal has been to seek to limit the magnitude of selection effects and to provide reasonable bounds on ATT estimates for the effect of health insurance.

Our results imply that in the longer run, much as other studies find in the near term, health insurance does not have a large impact on overall health or mortality for the near-elderly - a group of uninsured for which an effect might be plausible. This implies that the health insurance expansion provided by the Affordable Care Act is not likely to greatly affect overall population health or mortality. It may, of course, have an impact on particular subgroups, such as diabetics, who could benefit from earlier diagnosis and treatment.

We find lower health-care utilization by the initially uninsured in earlier waves, and roughly equal utilization once both groups reach Medicare age, with a tilt toward lower use by the previously uninsured. We find no evidence of a rebound effect. Once insured, the initially uninsured do not consume more health care than the initially insured. The moderate differences in utilization that we find-many of which likely involve marginal choices to seek health care-are consistent with small resulting differences in health and mortality. 


\section{ACKNOWLEDGEMENTS}

We thank Michael Geruso, Roee Gutman, Bentley MacLeod, David Orentlicher, Seth Seabury, participants in conferences and workshops at the Annual Health Economics Conference (2014), Bar Ilan Law School, Columbia Law School, the Conference on Empirical Legal Studies 2013, the Cornell Law School Conference on Empirical Health Law, the Federal Reserve Bank of Chicago, Harvard Law School, the Interdisciplinary Center Herzliya Law School, the National University of Singapore School of Business, Northwestern Law School, the Public Health Law Research Program of the Robert Wood Johnson Foundation annual meeting, Tinbergen Institute, and University of Texas Law School for comments, and Taylor Kelley, Arend Kuyper, and Mame Maloney for research assistance.

\section{REFERENCES}

Abadie, Alberto, and Guido W. Imbens. 2012. "Bias Corrected Matching Estimators for Average Treatment Effects." Journal of Business and Economic Statistics 29 (1): 111.

Allen, Heidi, Katherine Baicker, Amy Finkelstein, Sarah Taubman, Bill J. Wright, and the Oregon Health Study Group. 2010. "What the Oregon Health Study Can Tell Us about Expanding Medicaid." Health Affairs 29 (8): 1498-1506.

Altonji, Joseph G., Todd E. Elder, and Christopher R. Taber. 2005. "Selection on Observed and Unobserved Variables: Assessing the Effectiveness of Catholic Schools." Journal of Political Economy 113 (1): 151-184.

Baicker, Katherine, Sarah L. Taubman, Heidi L. Allen, Mira Bernstein, Jonathan Gruber, Joseph P. Newhouse, Eric C. Schneider, Bill J. Wright, Alan M. Zaslavsky, and Amy N. Finkelstein. 2013. "The Oregon Experiment-Effects of Medicaid on Clinical Outcomes." New England Journal of Medicine 368 (18): 1713-22.

Baker, David W., Joseph Feinglass, Ramon Durazo-Arvizu, Whitney P. Witt, Joseph J. Sudano, and Jason A. Thompson. 2006. "Changes in Health for the Uninsured After Reaching Age-Eligibility for Medicare.” Journal of General Internal Medicine 21 (11): 1144-49.

Baker, David W., Joseph J. Sudano, Jeffrey M. Albert, Elaine A. Borawski, and Avi Dor. 2001. "Lack of Health Insurance and Decline in Overall Health in Late Middle Age." New England Journal of Medicine 345 (15): 1106-12.

_. 2002. "Loss of Health Insurance and the Risk for a Decline in Self-Reported Health and Physical Functioning." Medical Care 40 (11): 1126-31.

Baker, David W., Joseph J. Sudano, Ramon Durazo-Arvizu, Joseph Feinglass, Whitney P. Witt, and Jason Thompson. 2006. "Health Insurance Coverage and the Risk of Decline in Overall Health and Death among the Near-Elderly 1992-2002." Medical Care 44 (3): 277-82.

Bhattacharya, Jay, M. Kate Bundorf, Noemi Pace, and Neeraj Sood. 2011. "Does Health Insurance Make You Fat?" In Economic Aspects of Obesity, edited by Michael Grossman and Naci H. Mocan, 35-64. Chicago: University of Chicago Press.

Brown, David W., Amanda E. Kowalski, and Ithai Z. Lurie. Forthcoming. "The Long-Term Impact of Medicaid Expansions on Eligible Children." Working paper. http://www.econ.yale.edu/ ak669/medicaid.latest.draft.pdf. 
Campbell, Donald T. 1969. "Prospective: Artifact and Control." In Artifact in Behavioral Research, edited by Robert Rosenthal and Ralph L. Rosnow, 351-82. New York: Academic Press.

Card, David, Carlos Dobkin, and Nicole Maestas. 2004. "The Impact of Nearly Universal Insurance Coverage on Health Care Utilization and Health: Evidence from Medicare." NBER Working Paper No. 10365. http://ssrn.com/abstract=516706.

_ 2008. "The Impact of Nearly Universal Insurance Coverage on Health Care Utilization: Evidence from Medicare." American Economic Review 98 (5): 2242-58.

2009. “Does Medicare Save Lives?” Quarterly Journal of Economics 124 (2): 597636.

Chandra, Amitabh, and Jonathan Skinner. 2012. "Technology Growth and Expenditure Growth in Health Care." Journal of Economic Literature 50 (3): 645-80.

Chay, Kenneth Y., Daeho Kim, and Shailender Swaminathan. 2010. "Medicare, Hospital Utilization and Mortality: Evidence from the Program's Origins." Working paper. http://www.chicagofed.org/digital_assets/others/events/2010/health_care_conference /paper_chay.pdf.

Courtemanche, Charles, and Daniela Zapata. 2014. "Does Universal Coverage Improve Health? The Massachusetts Experience." Journal of Policy Analysis and Management 33 (1): 36-69.

Crump, Richard K., V. Joseph Hotz, Guido W. Imbens, and Oscar Mitnik. 2009. "Dealing with Limited Overlap in Estimation of Average Treatment Effects." Biometrika 96 (1): 187-99.

Currie, Janet, and Jonathan Gruber. 1996. “Saving Babies: The Efficacy and Cost of Recent Changes in the Medicaid Eligibility of Pregnant Women." Journal of Political Economy 104 (6): 1263-96.

Dafny, Leemore, and Jonathan Gruber. 2005. "Public Insurance and Child Hospitalizations: Access and Efficiency Effects." Journal of Public Economics 89 (1): 109-29.

Dor, Avi, Joseph Sudano, and David W. Baker. 2006. "The Effect of Private Insurance on the Health of Older, Working Age Adults: Evidence from the Health and Retirement Study." Health Services Research 41 (3p1): 759-87.

Dor, Avi, and Eleonora Umapathi. 2014. "Health Insurance and Health." In Encyclopedia of Health Economics, edited by Anthony Culyer, 357-64. Amsterdam: Elsevier.

Dorn, Stan. 2008. "Uninsured and Dying Because of It: Updating the Institute of Medicine Analysis on the Impact of Uninsurance on Mortality." Urban Institute report. http://www.urban.org/UploadedPDF/411588_uninsured_dying.pdf.

Dow, William H. 2004. "The Introduction of Medicare: Effects on Elderly Health.” Working paper. University of California, Berkeley.

Doyle, Joseph J. Jr. 2005. "Health Insurance, Treatment and Outcomes: Using Auto Accidents as Health Shocks." Review of Economics and Statistics 87 (2): 256-70.

Families USA. 2012. "Dying for Coverage: The Deadly Consequences of Being Uninsured." http://www.familiesusa.org/issues/uninsured/publications/dying-for-coverage.html.

Finkelstein, Amy, and Robin McKnight. 2008. "What Did Medicare Do? The Initial Impact of Medicare on Mortality and Out of Pocket Medical Spending." Journal of Public Economics 92 (7): 1644-68. 
Finkelstein, Amy, Sarah Taubman, Bill Wright, Mira Bernstein, Jonathan Gruber, Joseph P. Newhouse, Heidi Allen, Katherine Baicker, and the Oregon Health Study Group. 2012. "The Oregon Health Insurance Experiment: Evidence from the First Year." Quarterly Journal of Economics 127 (3): 1057-106.

Franks, Peter, Carolyn M. Clancy, and Marthe R. Gold. 1993. "Health Insurance and Mortality: Evidence from a National Cohort." Journal of the American Medical Association 270 (6): 737-41.

Fuchs, Victor R. 2004. “More Variation in Care, More Flat-of-the-Curve Medicine." Health Affairs 23 (October): VAR104-7.

Goodman-Bacon, Andrew. 2013. "Public Insurance and Mortality: Evidence from Medicaid Implementation." Working paper. Accessed October 17, 2013. http://wwwpersonal.umich.edu/ ajgb/medicaid_ajgb.pdf.

Goodnough, Abby, Robert Pear, and Richard Perez-Peña. 2013. "Opening Rush to Insurance Markets Hits Snags.” New York Times, October 2, A1.

Gutman, R., and D. B. Rubin. 2013. "Robust Estimation of Causal Effects of Binary Treatments in Unconfounded Studies with Dichotomous Outcomes." Statistics in Medicine 32 (11): 1795-814.

Hadley, Jack, and Timothy Waidmann. 2006. "Health Insurance and Health at Age 65: Implications for Medical Care Spending on New Medicare Beneficiaries." Health Services Research 41 (2): 429-51.

Hall, Mark A. 2011. "Access to Care Provided by Better Safety Net Systems for the Uninsured: Measuring and Conceptualizing Adequacy." Medical Care Research and Review 68 (4): 441-61.

Hosman, Carrie, Ben Hansen, and Paul Holland. 2010. "The Sensitivity of Linear Regression Coefficients' Confidence Limits to the Omission of a Confounder." Annals of Applied Statistics 4 (2): 849-70.

Imbens, Guido W., and Donald B. Rubin. 2015. Causal Inference in Statistics, Social, and Biomedical Sciences: An Introduction. New York: Cambridge University Press.

IOM (Institute of Medicine). 2002. Care Without Coverage: Too Little, Too Late. Washington, DC: National Academy Press.

Kang, Joseph D. Y., and Joseph L. Schafer. 2007. "Demystifying Double Robustness: A Comparison of Alternative Strategies for Estimating a Population Mean from Incomplete Data." Statistical Science 22 (4): 523-39.

Kasper, Judith D., Terence A. Giovannini, and Catherine Hoffman. 2000. "Gaining and Losing Health Insurance: Strengthening the Evidence for Effects on Access to Care and Health Outcomes." Medical Care Research and Review 57 (3): 298-318.

Kronick, Richard. 2006. "Commentary [on Hadley and Waidmann (2006)] Sophisticated Methods but Implausible Results: How Much Does Health Insurance Improve Health?” Health Services Research 41 (2): 452-60.

_ 2009. "Health Insurance Coverage and Mortality Revisited." Health Services Research 44 (4): 1211-31.

Lichtenberg, Frank R. 2002. "The Effects of Medicare on Health Care Utilization and Outcomes." In Frontiers in Health Policy Research, edited by Alan M. Garber, 5:27-52. Cambridge: MIT Press. 
Manski, Charles. 1990. "Nonparametric Bounds on Treatment Effects." American Economic Review 80 (2): 319-23.

McWilliams, J. Michael, Ellen Meara, Alan M. Zaslavsky, and John Z. Ayanian. 2007a. "Health of Previously Uninsured Adults After Acquiring Medicare Coverage." JAMA 298 (24): 2886-94.

- 2007b. "Use of Health Services by Previously Uninsured Medicare Beneficiaries." New England Journal of Medicine 357 (2): 143-53.

McWilliams, J. Michael, Alan M. Zaslavsky, Ellen Meara, and John Z. Ayanian. 2004. "Health Insurance Coverage and Mortality among the Near-Elderly." Health Affairs 23 (4): 223-33.

Miller, Sarah, and Laura Wherry. 2015. “The Long-Term Health Effects of Early Life Medicaid Coverage." Working paper.

Oster, Emily. 2016. "Unobservable Selection and Coefficient Stability: Theory and Evidence." Journal of Business \& Economic Statistics. http://doi.org/10.1080/07350015 .2016.1227711.

Polsky, Daniel, Jalpa A. Doshi, José Escarce, Willard Manning, Susan M. Paddock, Liyi Cen, and Jeannette Rogowski. 2009. "The Health Effects of Medicare for the NearElderly Uninsured.” Health Services Research 44 (3): 926-45.

Robins, James, and A. Rotnitzky. 2001. "Comment (on Bickel and Kwon, Inference for Semiparametric Models: Some Questions and an Answer)." Statistica Sinica 11 (4): 920-36.

Rosenbaum, Paul R. 1987. "The Role of a Second Control Group in an Observational Study." Statistical Science 2 (3): 292-316.

- 2009. Design of Observational Studies. New York: Springer.

- 2010. Observational Studies. 2nd ed. New York: Springer.

Shadish, William R., Thomas D. Cook, and Donald T. Campbell. 2002. Experimental and Quasi-experimental Designs for Generalized Causal Inference. Belmont, CA: Wadsworth.

Shigeoka, Hitoshi. 2014. "The Effect of Patient Cost Sharing on Utilization, Health, and Risk Protection.” American Economic Review 104 (7): 2152-84.

Skinner, Jonathan. 2012. "Causes and Consequences of Regional Variations in Health Care." In Handbook of Health Economics, edited by Thomas McGuire, Mark Pauly, and P. Pita Baros, 2:45-93. Amsterdam: North Holland.

Sommers, Benjamin D., Katherine Baicker, and Arnold M. Epstein. 2012. "Mortality and Access to Care among Adults After Medicaid Expansions." New England Journal of Medicine 367 (11): 1025-34.

Sommers, Benjamin D., Sharon K. Long, and Katherine Baicker. 2014. "Changes in Mortality After Massachusetts Health Care Reform: A Quasi-experimental Study.” Annals of Internal Medicine 160 (9): 585-94.

Sorlie, Paul D., Norman J. Johnson, Eric Backlund, and Douglas D. Bradham. 1994. "Mortality in the Uninsured Compared with That in Persons with Public and Private Health Insurance." Archives of Internal Medicine 154 (21): 2409-16. 
Weathers, Robert R. II, and Michelle Stegman. 2012. “The Effect of Expanding Access to Health Insurance on the Health and Mortality of Social Security Disability Insurance Recipients." Journal of Health Economics 31 (6): 863-75.

Wilper, Andrew P., Steffie Woolhandler, Karen E. Lasser, Danny McCormick, David H. Bor, and David U. Himmelstein. 2009. "Health Insurance and Mortality in US Adults." American Journal of Public Health 99 (12): 2289-95.

Wooldridge, Jeffrey M. 2010. Econometric Analysis of Cross Section and Panel Data. 2nd ed. Cambridge, MA: MIT Press.

Wu, Vivian Y., and Yu-Chu Shen. 2011. "The Long-Term Impact of Medicare Payment Reductions on Patient Outcomes.” NBER Working Paper No. 16859. http://ssrn.com /abstract $=1776794$. 